\title{
PENGENALAN PLC UNTUK MENINGKATKAN KEMAMPUAN LOGIKA ASESMEN KOMPETENSI MINIMAL (AKM) SISWA SMAN 1 JOGOROGO
}

\author{
Oleh: \\ Isa Rachman ${ }^{1}$, M. Basuki Rahmat ${ }^{2}$, Adianto ${ }^{3}$, li Munadhif ${ }^{4}$, Ryan Yudha A. ${ }^{5}$ \\ Politeknik Perkapalan Negeri Surabaya \\ isarachman@ppns.ac.id
}

\begin{abstract}
Abstrak
Asesmen Kompetensi Minimal (AKM) merupakan salah satu asesmen nasional yang digunakan pada tahun 2021 oleh Kementerian Pendidikan dan Kebudayaan untuk menggantikan ujian nasional tingkat SMA. AKM fokus mengukur kemampuan literasi dan numerikal melalui kemampuan logika dan pemahaman baca siswa. Berdasarkan laporan hasil tes PISA pada tahun 2018, kedua kompetensi ini menjadi masalah mendasar siswa di Indonesia. Untuk memicu peningkatan kemampuan logika siswa SMAN 1 Jogorogo, maka diberikan pengetahuan tambahan di luar kurikulum. Salah satunya melalui kegiatan pengenalan PLC yaitu, perangkat pemrograman berbasis logika. Kegiatan ini juga mampu meningkatkan kompetensi dalam literasi digital, teknologi dan manusia pada era revolusi industri 4.0 karena PLC banyak digunakan dibidang otomasi industri. Kegiatan dilaksanakan dengan metode daring melalui media Zoom dan Google untuk menciptakan ruang pembelajaran interaktif karena pada kondisi pandemi COVID-19. Dari pelaksanaan kegiatan, didapatkan hasil quiz peserta pada setiap pokok materi menunjukkan hasil cukup memuaskan dengan nilai rata-rata 74 dan hasil tes peserta pada akhir pembelajaran juga menunjukkan hasil cukup memuaskan dengan nilai rata-rata 76. Selain itu, dari hasil kuisioner peserta sebagai bentuk respon dari pelaksanaan kegiatan menunjukkan hasil baik. Dengan adanya kegiatan ini, PLC dapat dijadikan sebagai salah satu kegiatan ekstrakurikuler untuk meningkatkan kompetensi siswa SMAN 1 Jogorogo.
\end{abstract}

Kata Kunci : asesmen, kompetensi, logika, siswa, PLC.

\section{Abstract}

The Minimum Competency Assessment (AKM) is one of the national assessments used in 2021 by the Ministry of Education and Culture to replace the high school level national exam. AKM focuses on measuring literacy and numerical skills through students' logic skills and reading comprehension. Based on the report on the results of the PISA test in 2018, these two competencies are a fundamental problem for students in Indonesia. To trigger an increase in the logic skills of students at SMAN 1 Jogorogo, additional knowledge outside the curriculum is given. One of them is through the introduction of PLC which is logic-based programming tools. This activity is also able to increase competence in digital, technology and human literacy in the era of the industrial revolution 4.0 because PLC is widely used in the field of industrial automation. Activities are carried out using the online method through the Zoom and Google media to create interactive learning spaces due to the conditions of the COVID-19 pandemic. From the implementation of the activity, the results of the participant's quiz on each subject showed satisfactory results with an average score of 74 and the participant's test results at the end of the lesson also showed quite satisfactory results with an average score of 76. In addition, the results of the participants' questionnaires as a form of response to the implementation of the activities showed good results. With this activity, PLC can be used as an extracurricular activity to improve the competence of students of SMAN 1 Jogorogo.

Keywords : assesment, compentence, logic, student, PLC.

\section{PENDAHULUAN}

Asesmen nasional merupakan pemetaan mutu pendidikan untuk madrasah, sekolah maupun program kesetaraan jenjang mulai tingkat dasar sampai dengan menengah atas. Tujuan asesmen nasional adalah pemetaan dasar dari mutu pendidikan sebenarnya yang ada di lapangan untuk membantu tiap sekolah dan dinas pendidikan daerah terkait perbaikan proses pembelajaran dan peningkatan kondisi belajar yang kondusif. Selain itu, kebijakan ini juga bertujuan untuk memberikan gambaran mengenai dampak dari proses pembelajaran yang dilakukan pada tiap satuan pendidikan.

Asesmen nasional terdiri atas tiga bagian yaitu, Asesmen Kompetensi Minimum (AKM), survei karakter dan survei lingkungan belajar. Pelaporan hasil uji asesmen nasional berisi 
penjelasan terkait profil kekuatan dan lingkup perbaikan berupa nilai agregat tiap sekolah

dan dinas pendidikan daerah. Siswa peserta uji asesmen ini dipilih secara acak dari kelas 5 SD, 8 SMP dan 11 SMA dengan tujuan agar siswa dapat merasakan perbaikan proses pembelajaran setelah adanya asesmen.

Rencana pemerintah melalui Kementerian Pendidikan dan Kebudayaan pada tahun 2021 untuk menyelenggarakan asesmen nasioanal yaitu, AKM dan survei karakter sebagai pengganti ujian nasional pada akhir jenjang tingkat SMA telah memasuki langkah konkret. Asesmen ini akan menggambarkan tingkat pencapaian mutu kompetensi peserta didik sehingga menjadi gambaran mutu sekolah yang otentik bagi Kementerian Pendidikan dan Kebudayaan. Instrumen AKM akan menguji kemampuan logika dan pemahaman bacaan. Instrumen survei karakter akan merefleksi diri pada sebuah situasi dan pengalaman nyata.

AKM fokus mengukur kemampuan literasi dan numerikal siswa. Berdasarkan laporan hasil tes Program for International Student Assessment (PISA) tahun 2018, kedua aspek kompetensi ini menjadi masalah mendasar siswa di Indonesia. Kemampuan literasi siswa yang rendah juga dibuktikan dengan hasil penelitian yang telah dilakukan oleh Suciati, dkk. pada tahun 2014 yang mengidentifikasi kemampuan literasi siswa pada beberapa sekolah yaitu, SMAN 5 Surakarta, SMAN 7 Surakarta, SMAN 8 Surakarta, SMAN 1 Sumberlawang, SMAN 2 Karanganyar, MAN 1 Sragen dan SMAN 1 Jogorogo melalui aspek yang dikembangkan oleh PISA 2000 dan PISA 2003 dengan nilai persentase rata-rata yaitu, aspek konten $(34,4$ $\%)$, aspek proses $(32,61 \%)$ dan aspek konteks $(35,91 \%)$.

Kegiatan Pengabdian Kepada Masyarakat (PKM) ini dilaksanakan disalah satu sekolah dengan kemampuan literasi siswa yang masih rendah yaitu, SMAN 1 Jogorogo, Ngawi. Untuk memicu peningkatan kemampuan literasi dan numerikal melalui kemampuan logika dan pemahaman baca siswa SMAN 1 Jogorogo, maka diberikan pengetahuan tambahan yang tidak tercantum didalam kurikulum. Salah satunya melalui kegiatan pengenalan PLC yang merupakan perangkat pemrograman berbasis logika. Kegiatan PKM ini juga mampu meningkatkan kompetensi siswa dalam literasi sains digital, teknologi dan manusia pada era revolusi industri 4.0 karena PLC telah banyak digunakan dibidang otomasi industry

\section{METODE}

Kerangka pemecahan masalah kegiatan ini dipertimbangkan dari berbagai hal antara lain yaitu, tingkat kebutuhan dan permasalahan, situasi dan kondisi, IPTEK yang diterapkan, Sumber Daya Manusia (SDM) yang dimiliki, manfaat dan tingkat keberhasilan yang akan dicapai. Untuk merealisasikan kegiatan PKM ini sesuai dengan permasalahan yang telah ditemukan, maka pendekatan yang dilakukan meliputi yaitu, identifikasi, observasi, diskusi, sosialisasi, pelatihan dan evaluasi dengan langkah-langkah sebagai berikut,

\section{Persiapan}

Supaya kegiatan PKM ini berjalan dengan baik, maka langkah-langkah persiapannya sebagai berikut,

a. Melakukan identifikasi sekolah yang akan terlibat menjadi mitra PKM yaitu, SMAN 1 Jogorogo, Ngawi

b. Mengobservasi objek kegiatan yaitu, siswa SMAN 1 Jogorogo untuk memperoleh data atau informasi yang dibutuhkan antara lain yaitu, pelajaran, nilai, jadwal, dll.

c. Melakukan diskusi dengan tim pelaksana, dan instruktur kegiatan serta guru sekolah pendamping untuk penentuan mekanisme kegiatan

d. Menentukan peserta yaitu, siswa kelas 11 Jurusan IPA SMAN 1 Jogorogo sebanyak 15 orang

e. Penetapan materi beserta durasinya yang akan disampaikan antara lain yaitu, fitur, arsitektur, program, antarmuka, aplikasi dan troubleshooting

f. Menyiapkan dokumen, modul, bahan dan perangkat yang diperlukan

g. Menyusun jadwal pelaksanaan kegiatan

h. Melakukan sosialisasi ke mitra PKM terkait pelaksanaan kegiatan.

2. Pelaksanaan

Kegiatan ini dilaksanakan secara daring dengan media interaktif melalui Google dan Zoom karena masih pada kondisi pandemi COVID-19 dengan durasi 18 jam selama 3 (tiga) hari. Metode yang digunakan yaitu, ceramah dan tanya-jawab serta simulasi dengan mekanisme sebagai berikut,

a. Perangkat lunak dan prosedur instalasinya diberikan melalui flashdisk

b. Materi dan latihan diberikan sesuai jadwal melalui Google Classroom

c. Peserta mempelajari materi dan latihan sebelum sesi tanya-jawab materi 
d. Sesi tanya-jawab materi antara peserta dan instruktur melalui Google dan Zoom

e. Setiap akhir bagian materi, peserta wajib menjawab kuis melalui Google Classroom

f. Diakhir kegiatan, peserta wajib mengikutites melalui Google Classroom dan mengisi kuesioner melalui media Google Form

\section{HASIL DAN PEMBAHASAN}

Kegiatan PKM ini dilaksanakan selama 3 (tiga) hari mulai dari tanggal 28-30 September 2020 jam 08.00-14.00. Satu minggu sebelum pelaksanaan kegiatan dilakukan sosialisasi ke mitra PKM dengan tujuan untuk memaparkan secara singkat deskripsi kegiatan yang akan dilaksanakan sekaligus penyerahan flashdisk berisikan perangkat lunak dan kartu perdana kuota internet yang akan digunakan pada saat kegiatan.

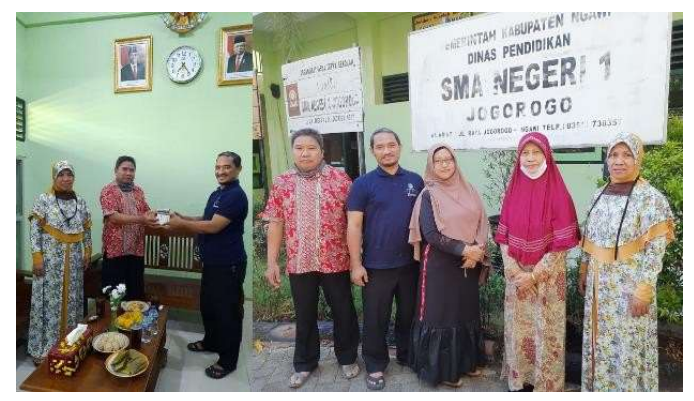

Gambar 1. Sosialisasi Kegiatan

Materi diberikan dalam bentuk slide (.ppt), dokumen (.pdf) dan video interaktif dengan pokok bahasan terbagi menjadi 3 (tiga) bagian sebagai berikut,

1. Bagian I : Omron CJ1M PLC overview, system configuration, communication and addressing

2. Bagian II : I/O (Input - Output) connection and wiring, basic instruction

3. Bagian III : HMI (Human Machine Interface) design, software interfacing, problem and fault diagnostic.

Materi tersebut disampaikan selama 18 jam oleh 5 (lima) orang instruktur yang berasal dari tenaga pendidik Politeknik Perkapalan Negeri Surabaya (PPNS).

Komputer atau laptop yang digunakan oleh peserta, minimal harus memiliki spesifikasi sebagai berikut,

Rekomendasi prosesor oleh Microsoft
e-ISSN: 2502-6518

Rekomendasi memori oleh Microsoft

Sistem operasi Windows 7/8/10 32/64 bit

Kapasitas penyimpanan minimal 6 GB

Resolusi layar 1024x768 16 bit

Komunikasi RS-232C/USB/ethernet port. Agar spesifikasi minimal komputer atau laptop tersebut terpenuhi, maka SMAN 1 Jogorogo menyediakan bantuan fasilitas bagi seluruh peserta sehingga kegiatan berjalan baik dan lancar. Seluruh kegiatan ini dilaksanakan di Laboratorium Komputer SMAN 1 Jogorogo dengan tetap menjaga dan mematuhi protokol kesehatan COVID-19.

Pada hari pertama, pokok bahasan bagian I yang diberikan pada peserta antara lain yaitu, pengenalan perangkat PLC meliputi perangkat keras dan perangkat lunak, konfigurasi sistem meliputi susunan catu daya, CPU, modul I/O digital dan analog, komunikasi meliputi sistem koneksi dengan komputer atau laptop, dan pengalamatan meliputi setting alamat sesuai konfigurasi sistem.

Pada hari kedua, pokok bahasan bagian II yang diberikan pada peserta antara lain yaitu, sistem koneksi dan pengkabelan I/O meliputi rangkaian metode sinking dan sourcing sensor dan aktuator, dan perintah dasar meliputi bit logic, set, reset, keep, timer, counter, move dan compare.

Pada hari ketiga, pokok bahasan bagian III yang diberikan pada peserta antara lain yaitu, desain HMI meliputi layar, warna, teks, tombol, lampu dan timer, antarmuka perangkat lunak meliputi koneksi ladder diagram dengan HMI, dan diagnosa kesalahan dan masalah meliputi perangkat keras dan perangkat lunak.

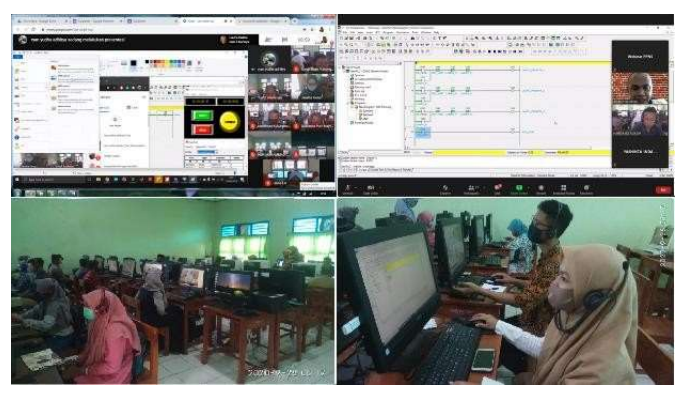

Gambar 2. Pelaksanaan Kegiatan

Selain mempelajari materi yang diberikan, peserta diberi latihan untuk dikerjakan secara mandiri. Peserta juga diberikan kesempatan untuk tanya-jawab dengan instruktur terkait materi yang telah dipelajari. Sebagai bentuk 
evaluasi dari kegiatan ini, maka peserta wajib menjawab kuis yang diberikan disetiap akhir bagian materi dan tes yang diberikan diakhir kegiatan. Soal kuis yang diberikan berbentuk multiple choice dan soal tes yang diberikan berbentuk simulasi interaktif. Seluruh materi, kuis dan tes diberikan melalui media Google Classroom yang dapat diakses oleh seluruh peserta.

Dari hasil kuis seluruh peserta pada 3 (tiga) bagian pokok bahasan terlihat menunjukkan hasil cukup memuaskan dengan nilai rata-rata yaitu, 74. Dari hasil tes seluruh peserta diakhir kegiatan ini terlihat menunjukkan hasil cukup memuaskan dengan nilai rata-rata yaitu, 76 . Hal tersebut menunjukkan bahwa sebenarnya siswa SMAN 1 Jogorogo memiliki kemampuan literasi dan numerikal yang cukup baik.

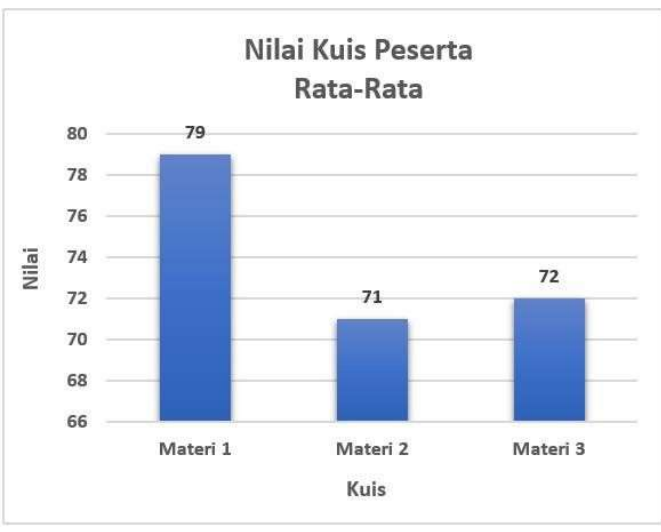

\section{Gambar 3. Nilai Kuis Peserta Rata-Rata}

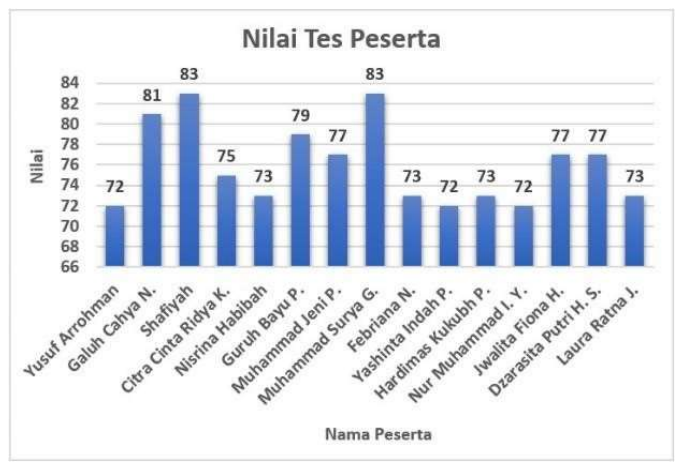

Gambar 4. Nilai Tes Peserta

Diakhir kegiatan ini, seluruh peserta wajib mengisi kuesioner melalui media Google Form sebagai bentuk respon atau tanggapan dari pelaksanaan kegiatan meliputi sistematika isi materi, kemudahan pemahaman isi materi, cara atau teknik penyampaian materi, alokasi waktu penyampaian materi, interaksi instruktur dan peserta, kemampuan instruktur, alokasi waktu tanya-jawab materi, metode (media, fasilitas, mekanisme) dan manfaat kegiatan.

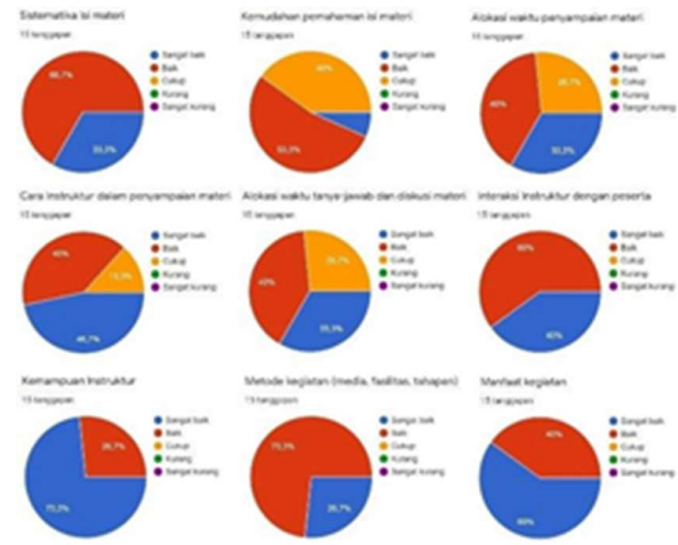

Dari hasil kuesioner yang telah diisi oleh seluruh peserta terlihat menunjukkan hasil baik. Masukan berupa saran yang didapatkan dari hasil kuesioner yaitu, kurangnya alokasi waktu saat penyampaian materi. Hal tersebut dikarenakan oleh keterbatasan dalam kondisi pandemi COVID-19 sehingga seluruh materi tidak dapat tersampaikan. Selain itu, kegiatan ini juga mampu memberikan gambaran pada peserta terkait kompetensi SDM yang harus dimiliki pada era revolusi industri 4.0.

Agar kemampuan literasi dan numerikal siswa dapat terukur, maka diharapkan adanya kegiatan pelatihan lebih lanjut karena kegiatan ini hanya sebagai pemicu untuk peningkatan kemampuan literasi dan numerikal khususnya kemampuan logika dan pemahaman baca siswa SMAN 1 Jogorogo.

Kegiatan PKM ini dapat terlaksana dengan baik berkat kerjasama antara Pusat Penelitian dan Pengabdian kepada Masyarakat PPNS dengan SMAN 1 Jogorogo, Ngawi khususnya guru pendamping sekolah yang telah banyak membantu dan berperan aktif.

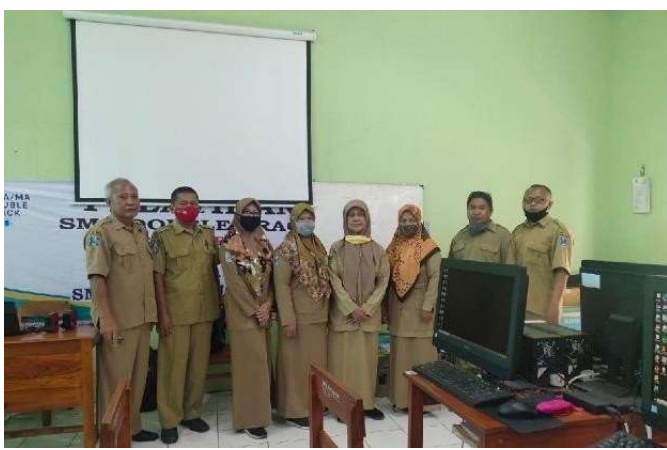


Gambar 6. Guru Pendamping Sekolah

\section{SIMPULAN DAN SARAN}

\section{Simpulan}

Dari hasil pelaksanaan kegiatan yang telah dilakukan, maka didapatkan simpulan sebagai berikut,

1. Kegiatan telah dilaksanakan dengan baik sesuai dengan tujuan yaitu, peningkatan kemampuan literasi dan numerikal melalui kemampuan logika dan pemahaman baca siswa SMAN 1 Jogorogo

2. Kegiatan diikuti oleh 15 orang siswa SMAN 1 Jogorogo dan difasilitasi oleh SMAN 1 Jogorogo serta dilaksanakan secara daring karena dalam kondisi pandemi COVID-19 dengan durasi 18 jam selama 3 (tiga) hari dari tanggal 28-30 September 2020

3. Hasil kuis peserta pada 3 (tiga) bagian pokok bahasan menunjukkan hasil cukup memuaskan dengan nilai rata-rata yaitu, 74

4. Hasil tes akhir peserta menunjukkan hasil cukup memuaskan dengan nilai rata-rata yaitu, 76

5. Hasil kuisioner peserta sebagai bentuk respon atau tanggapan dari pelaksanaan kegiatan menunjukkan hasil baik.

\section{Saran}

Dari hasil pelaksanaan kegiatan yang telah dilakukan, maka didapatkan saran perbaikan untuk pelaksanaan kegiatan pada masa yang akan datang sebagai berikut,

1. PLC dapat menjadi salah satu kegiatan ekstrakurikuler untuk memicu peningkatan kemampuan literasi dan numerikal melalui kemampuan logika dan pemahaman baca siswa SMAN 1 Jogorogo.

2. Diperlukan kegiatan pelatihan lebih lanjut agar kemampuan literasi dan numerikal siswa dapat benar-benar terukur, misalkan pelatihan literasi numerasi melalui program GLN (Gerakan Literasi Nasional).

3. PLC dapat menjadi salah satu kegiatan yang memberikan gambaran mengenai kompetensi SDM yang diperlukan pada era revolusi industri 4.0.

4. Tidak seluruh materi dapat tersampaikan dikarenakan keterbatasan dalam kondisi pandemi COVID-19 sehingga pada masa

\section{e-ISSN: 2502-6518}

yang akan datang dapat melanjutkannya dengan materi secara berkesinambungan melalui Pusat Penelitian dan Pengabdian Masyarakat Politeknik Perkapalan Negeri Surabaya.

\section{DAFTAR PUSTAKA}

Aisyah A. 2020. Kemampuan Numerasi Siswa Kelas VIII Berdasarkan Kognitif Penalaran Melalui Pembelajaran Berbasis Masalah. Universitas Sriwijaya. Palembang.

Anonimous. 2020. Asesmen Kompetensi

Minimum.www.kemdikbud.go.id.

Anonimous. 2019. Hasil PISA Indonesia 2018. Akses Makin Meluas, Saatnya Tingkatkan Kualitas. www.kemdikbud.go.id.

Cheria D, Sukarmin, Yohanes R. 2019.

Penerapan Model Pembelajaran GI-GI (Group Investigation-Guided Inquiry) pada Materi Momentum dan Impuls untuk Meningkatkan Kemampuan Literasi Sains Siswa. Jurnal Materi dan Pembelajaran Fisika Volume 9 Nomor 2.

Noorman R, Ryan Y, Aliy H, 2017. Praktikum Programmable Logic Controller. Politeknik Perkapalan Negeri Surabaya.

OMRON. 2018, W394 E1-13 CJ CS NSJ Programming Manual, Japan : OMRON CORPORATION.

Ta'ali, Aswardi M, Doni T. 2019. Pelatihan PLC dan Elektropneumatik untuk Meningkatkan Kompetensi Profesional Guru SMK Bidang Ketenagalistrikan : Implementasi Revolusi Industri 4.0. Jurnal Teknik Elektro dan Vokasional Volume 5 Nomor 2.

Weny I, Pauladie S, Ira P. 2019. PKM Pelatihan Pemrograman Dasar PLC untuk SMK Ketintang Surabaya. Seminar Nasional Sains dan Teknologi Terapan VII 